\title{
Introduction to the Diagnostic Modeling System (DMS)
}

\section{US Army Corps of Engineers ${ }_{\circledast}$}

by Nicholas C. Kraus

PURPOSE: The Coastal Engineering Technical Note (CETN) described herein introduces the methodology and technical products associated with the Diagnostic Modeling System (DMS) that is being developed to assist U.S. Army Corps of Engineers (USACE) Divisions and Districts in reducing the frequency and cost of dredging.

BACKGROUND: As described in CETN IV-22 (Rosati and Kraus 2000), "Shoal-Reduction Strategies for Entrance Channels," from fiscal year (FY) 1995 through 1998 the Corps dredged an average of 198 million $\mathrm{m}^{3} / \mathrm{year}$ from Federal channels. Maintenance dredging accounted for an average of 89 percent of this volume, with new work and emergency dredging comprising the remainder. A reduction in maintenance and emergency dredging represents a significant costand timesaving measure for the operation and maintenance (O\&M) of Corps waterways. Such savings can be cumulative over the life of a project and can be reprogrammed to other O\&M projects.

CETN IV-17 (Pope 1997) classifies shoaling of inlet channels through consideration of geomorphologic characteristics. CETN IV-22 discusses managerial actions that can be taken to reduce deposition in channels and the associated dredging costs and quantities. These include the following:

a. Be alert to existing and past shoaling patterns, coastal processes at the site, and ongoing projects. This must occur on both local and regional scales.

$b$. Plan ahead for anticipated increases in dredging, rather than reacting to an emergency situation.

c. Plan to allow modification of designs.

$d$. Evaluate the success or failure of each implementation so that knowledge is gained through the process. Document and share findings.

e. Revise designs based on improved knowledge.

The present CETN describes an emerging system and selected products under development to support engineering actions that may be taken to reduce the frequency and cost of dredging. The DMS is intended to provide a rapid, yet reliable capability for identifying and evaluating navigation channel operations and maintenance $(\mathrm{O} \& \mathrm{M})$ alternatives based on limited information about the hydrodynamic and sediment-transport conditions at a site. The DMS gives a diagnosis of a problem shoaling area (in contrast to conducting expensive and time-consuming studies), together with guidance for determining possible solutions. The DMS can also contain dredging and associated records to document shoaling patterns and measures taken. 
The economic lever underlying the DMS concept is that a low-level analysis can yield substantial cost savings without interrupting ongoing O\&M activities and schedule. The DMS is intended to provide feasible alternatives within the dredging cycle of the subject project. The application time and effort in applying the DMS are expected to be relative to the maintenance interval of the project.

STRATEGY: The DMS is centered on an experienced-based methodology for solving sediment-shoaling problems. It comprises a suite of diagnostic tools intended for application by engineers engaged in the planning, design, and maintenance of navigation projects, channels, and waterways. As such, the DMS takes a common sense approach to guide the engineer through the systematic identification and characterization of shoaling problems, determination of their causative factors, and the development of practical, cost-effective solutions. To accomplish this, the DMS methodology provides a suite of engineering guides, procedures, and analytical tools, all of which are founded upon the principles of fluid dynamics and sediment transport. These tools can be applied either independently or in combination with coastal hydrodynamic models.

As a diagnostic procedure, the DMS is not intended to provide the level of detailed information required for final design or for in-depth study of a newly authorized project. Rather, it is primarily intended to function as a screening tool to rapidly diagnose existing shoaling problems, to categorize them according to their key characteristics, and to identify corrective actions that can be taken within the project's existing authorization. The entire DMS diagnostic procedure should be capable of completion within a time span shorter than the historical project dredging cycle.

DMS COMPONENTS: The DMS procedure is exercised through its three components called the Manual, the Data Manager, and the Analytical Toolbox. Typically, these procedures are applied in the order listed.

\section{Manual}

The DMS Manual is a Web-based reference document containing definition sketches, photographs of examples, and, in the future, remediation information for different shoaling categories based on case examples. The manual may be accessed from http://www.taylorengineering.com/DMShome/DMSDefault.htm and by clicking on title links listed in Table 1 if this CETN is being read as a hyperlinked document. The site is hosted at a consulting company assisting in development of the DMS. The Manual functions as a "field guide" in classifying shoaling by the mechanisms that create the shoaling pattern and the geometric or morphologic situation (e.g., Gosselin, Craig, and Taylor 1999; Kraus, Mark, and Sarruff 2000).

Because a principal feature of the Manual is visual identification, it is a Web-based evolving document that is anticipated to expand as more examples and processes are found. At present, the Manual contains six major categories as listed in Table 1, each category containing several types of sediment shoaling patterns and causes. 


\section{Table 1}

\section{Present Content of DMS Manual}

1. Horizontal Channel Expansion

- Ebb Tidal Shoal

- Flood Tidal Shoal

- Areas of Shoreline Recession

2. Vertical Channel Expansions

- Cross Channel Flow

- In Line Channel Flow

3. Sheltered Areas

- Downstream of Hardened Structures

- Downstream of Erodible Features

4. Changes in Channel Alignment

- Inside of Channel Bends

- Structurally Redirected Flows
5. Multiple Channels

- Branches

- Confluences and Intersections

- Riverine Sediment Sources

6. Enhanced Sediment Forcing

- Channel Crossing by Large Scale Eddies

- Wind-Wave Sediment Suspension

- $\quad$ Littoral Drift

- $\quad$ Adjacent to Wind-Blown Sediment Transport (Across Shore)

- $\quad$ Adjacent to Wind-Blown Sediment Transport (Along Shore)

- Breaching

- Overwashing

Figure 1 is a sample page from the Manual, Category 1 - "Horizontal Channel Expansion," and subcategory of "Expansion into Bay - Flood Tidal Shoal." Two examples are given on this particular page, for Bakers Haulover, FL, and Shinnecock Inlet, Long Island, NY. At both locations, the flood shoal is growing with associated deposition in the adjacent navigation channels. The sketch and photographs allow identification and categorization of the shoaling process.

Growth of large flood shoals indicates a possible flood dominance, that is, the flood flow is stronger but of shorter duration than the ebb flow. An example is shown in Figure 2, which is a plot of velocity measured in the middle of Shinnecock Inlet. Because the sediment transport rate is proportional to some large power of the velocity, for example, the velocity cubed, the stronger flowed flow will tend to sweep bayward sediment that is deposited into the channel by the longshore current. The plot in Figure 2 is translated upward (toward flood), indicating a mean trend toward filling of the bay during that time. Prior to the time interval shown in this plot, the bay level had been lowered by a wind that had forced water out of the inlet.

Depending upon the situation, possible solutions for the grown of flood shoals that may encroach into bay side navigation channels include: moving the channel further bayward from the inlet and the flood shoal; dredging a deposition basin between the channel and the flood shoal, from which captured sediment might be pumped to the downdrift beach as nourishment; and to modify the jetties or channel in such a way as to reduce the flood dominance. 


\section{CLASS: Horizontal Channel Expansion SUBCLASS: Expansion into Bay - Flood Tidal Shoal}

Description: A flood shoal forms on the interior of a tidal inlet from the

sediment transported by the flood tide. Typically is either one large shoal, two approximately symmetric shoals, or a bat-shaped shoal.

Processes: Flood-tidal current transports littoral material through the inlet. Upon experiencing the calm waters of the interior, sediments accumulate. The decrease in velocity is due to the horizontal spreading of the flood jet.
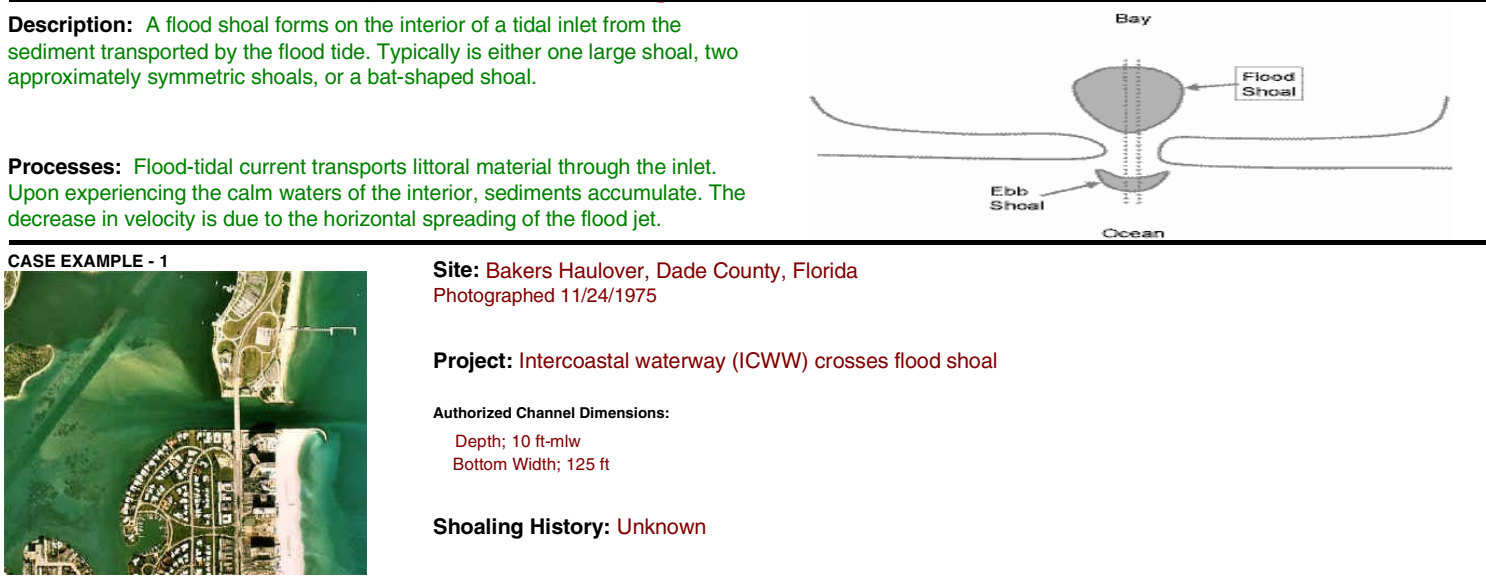

Site: Bakers Haulover, Dade County, Florida Photographed 11/24/1975

Project: Intercoastal waterway (ICWW) crosses flood shoal

Authorized Channel Dimensions:

Depth; $10 \mathrm{ft}-\mathrm{mlw}$

Bottom Width; $125 \mathrm{ft}$

Shoaling History: Unknown

CASE EXAMPLE - 2 Morang, A. (1999). Coastal Inlets Research Program, Shinnecock Inlet, New York, Site Investigation, Report 1, Morphology and Historical Behavior, Technical Report CHL-98-32, US Army Engineer Research and Development Center, Vicksburg, MS.

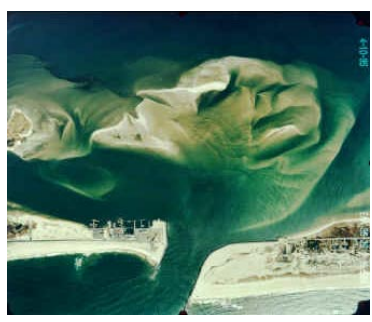
Site: Shinnecock Inlet, Long Island, New York

Photographed 4/10/95

Project: Federal Navigation Project from the Atlantic Ocean through the inlet to the Long Island Intracoastal Waterway (LIIW)

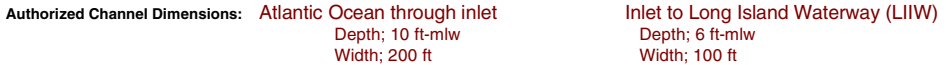

Shoaling History:

Total flood shoal volume (cu yd), including dredged channels directly north of barrier island

\begin{tabular}{|c|c|}
\hline Sep 1938 & Inlet Opened by Hurricane \\
\hline Jul-Aug 1949 & 678,000 \\
\hline Nov 1955 & 638,000 \\
\hline
\end{tabular}

Figure 1. Sample page from DMS Manual

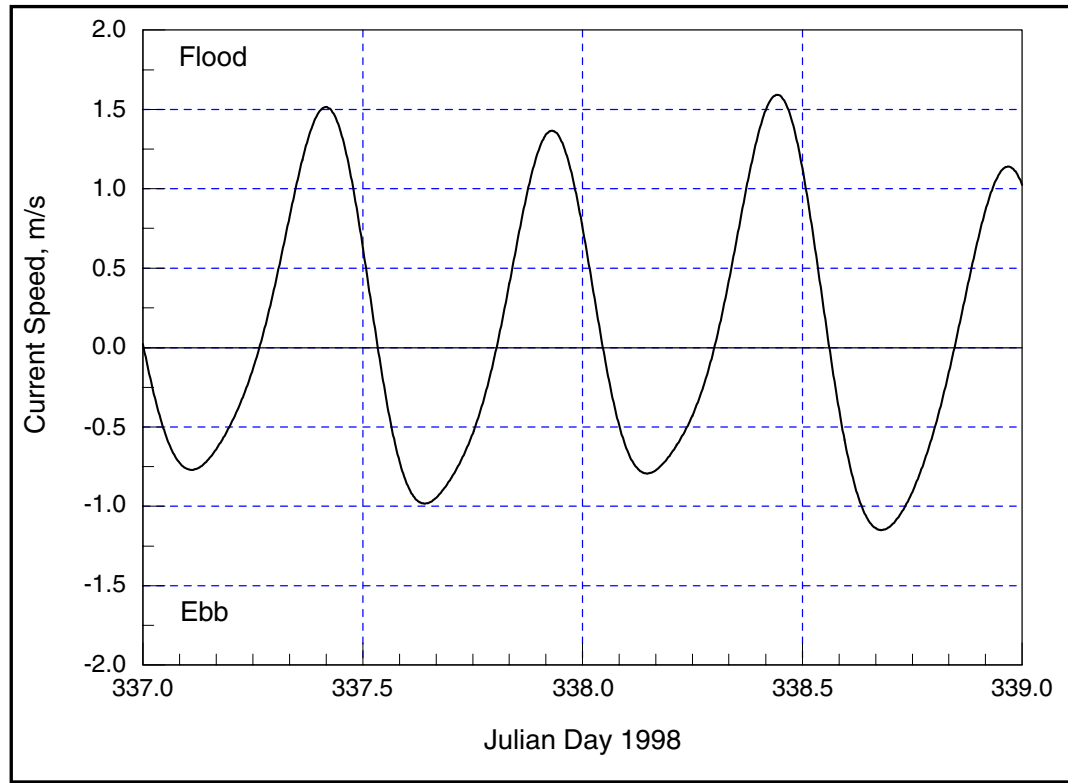

Figure 2. Time series of current measured near center of Shinnecock Inlet, NY, showing a strong tendency for flood dominance 


\section{Data Manager}

The Data Manager is a suite of computer programs embedded in a Geographic Information System (GIS) and is scheduled for release in October 2000. The Manager allows the user to organize and view relevant information within a project area. Examples of data residing in the Manager include digitized bathymetric surveys, aerial photographs, GIS coverages, shoaling history, and costs. This component gives organization and access to all graphical, numerical, and narrative information associated with a maintained channel. Interpretative and analytical applications comprising the Manual and the Analytical Toolbox can take advantage of the data contained in the Data Manager and its capability to output information in the appropriate format for use by these tools.

The Data Manager is an extension of the commercially available GIS software package ArcView (Version 3.1). The user interface of ArcView can be customized to extend the functionality of the package. These capabilities are leveraged to tailor the extension specifically to the goals of the DMS. Multiple data formats can be accessed and manipulated within ArcView, such as CAD drawings, GIS coverages, ArcView shapefiles, georeferenced photography, and ASCII point data. In combination with the Data Manager User's Guide, the Manager is operated with a user-friendly interface. Wizards assist users in multistep processes such as development of a comprehensive project database. The Data Manager also communicates with the Hydraulic Processes Analysis System (HyPAS) as described in CETN-IV-23 (Pratt and Cook 1999), another ArcView extension developed to analyze a wide variety of types of data generated by field measurements or by numerical models. The HyPAS thus becomes part of the Analytical Toolbox described in the next section.

Data Manager development focuses on seven general functional areas. The first four areas automate the project setup process, and the remaining areas allow analysis of these organized data sets to produce consistently formatted output. The Getting Started page introduces users to the general functionality of the Data Manager and provides direct links to the Coastal Inlets Research Program and DMS Web sites, help files, and tutorials. The "Project Set-Up Wizard" assists the initial Data Manager setup phase of a project, producing an organized and comprehensive project database. The Stationing Tool imports center-line and corresponding stationing information from user-defined ASCII files for any authorized navigation channels in the area. The Survey Conversion Tool imports new and historic bathymetric surveys, in multiple formats, and converts them to a format compatible with the Data Manager's analysis components. The Station Profile Display comprises the first analysis component. Multiple cross sections can be displayed at either user-defined areas or along predefined stations. The Volume Calculator determines volumetric differences between bathymetric surveys or between a survey and the predefined channel template. Finally, the Dredging Record Center imports, organizes, and displays past dredging record information. After these data are entered to the comprehensive relational database, automated queries can be generated through the user interface. It is anticipated that consistently formatted reports will contribute toward standardizing dredgingrelated reports. The Data Manager will be introduced in a CETN scheduled for publication in October 2000. 


\section{Analytical Toolbox}

The Analytical Toolbox is a system of calculation tools and guidance documents assembled for understanding and quantifying shoaling conditions and for formulating and evaluating alternatives to reduce dredging. The calculation tools portion of the Toolbox consists primarily of analytical and simple numerical models for estimating hydrodynamics and sediment transport in and around channels for a variety of situations. For rapid application within the DMS methodology, these tools are easy to use as stand-alone applications and are readily applied. For more detailed analyses, guidance documents refer the engineer to larger, more powerful infraDMS models (Gosselin, Craig, and Taylor 1999; Kraus, Mark, and Sarruff 2000). Also contained in guidance documents is information on useful graphical display formats and interpretative techniques for diagnosing shoaling areas, as described in CETN-IV-27 (Gosselin, Taylor, and Craig 2000). These guidance documents contain examples and discussions of standardized output formats from which the mechanisms and patterns associated with shoaling become easier to identify. Standardized output formats facilitate acquiring an experience base with which to compare other shoaling investigations.

The calculation tools cover utilities ranging in complexity from simple estimates of fetch-limited wave height to jet flow and channel infilling models. Presently, the utilities listed below have been selected for inclusion into the Analytical Toolbox.

Ebb Jet Model. This tool allows examination of the ebb or flood jet issuing from an inlet. Based on the work by Ozsoy and Ünlüata (1982), this program calculates the velocity distribution of an ebb- or flood-tidal jet taking into account lateral mixing and entrainment, bottom friction, one-dimensional bathymetric changes and ambient currents. For use on shoaling problems in channels through tidal inlets, this tool provides estimates of velocity magnitudes that drive sediment transport calculations. It also provides estimates of sediment transport through a sediment transport function developed by Van Rijn (1984).

HyPAS. This system was developed for analyzing, visualizing, and archiving hydrodynamic and other field data taken at inlets and related estuarine and coastal waters (Pratt and Cook 1999). HyPAS is also applicable to riverine and laboratory applications. Modern electronic instrumentation produces large amounts of data that may not be readily accessed because the engineer or scientist does not have an effective way to visualize and analyze it within the project time schedule. Tools in HyPAS address this problem. The system provides ready capability to visualize, analyze, reduce, and efficiently plot data from large and small data sets. Additionally, HyPAS takes advantage of geographically referenced data of high spatial accuracy. The DMS Data Manager and HyPAS operate as coordinated applications with ArcView.

Fetch-Limited, Wind-Generated Wave Model. This tool will calculate the wave height and period associated with wind waves generated in shallow water. This information can be entered in the Sediment Movement Calculator to determine whether wave driven sediment transport is the cause of channel shoaling.

Sediment Transport Calculator. This program provides estimates of sediment transport at a point. It calculates sediment transport from hydrodynamic conditions (both currents and waves) 
and sediment characteristics. Input to the Calculator can be estimates of waves and currents based upon experience or values taken from numerical models. The Sediment Transport Calculator determines the shear stress on the bed and associated sediment transport magnitude and direction. It also contains the Shield's diagram to identify areas of live bed (sediment motion) or clear water (no sediment movement).

CONCLUSIONS: The Corps mission to provide safe and navigable waterways requires maintenance dredging of inlet and entrance channels. Maintenance and emergency dredging comprise roughly 90 percent of the dredging volume and approximately 80 percent of the cost. Simple adjustments to existing operations can reduce dredging frequency and volume. The DMS aims to provide tools and a methodology to analyze areas of excessive shoaling and determine remedial measures.

ADDITIONAL INFORMATION: Questions about this CETN can be addressed to Dr. Nicholas C. Kraus (601-634-2016, fax 601-634-3080, e-mail: krausn@wes.army.mil). The author appreciates review of this CETN by colleague Mr. James Clausner, by Dr. Mark Gosselin, and Mr. Ken Craig of Taylor Engineering, Inc., Jacksonville, FL.

This CETN should be cited as follows:

Kraus, N. C. (2000). "Introduction to the Diagnostic Modeling System (DMS)," ERDC/CHL CETN-IV-28, U.S. Army Engineer Research and Development Center, Vicksburg, MS, , http://chl.wes.army.mil/library/publications/cetn/.

\section{REFERENCES:}

Gosselin, M. S., Craig, K. R., and Taylor, R. B. (1999). "DMS: Diagnostic Modeling System, Report 2: Reduction of sediment shoaling of the entrance Channel at East Pass, Florida," Technical Report CHL-99-19, U.S. Army Engineer Research and Development Center, Vicksburg, MS.

Gosselin, M. S., Taylor, R. B., and Craig, K. R. (2000). "Maximizing understanding of model results through graphical displays," ERDC/CHL CETN-IV-27, U.S. Army Engineer Research and Development Center, Vicksburg, MS, http://chl.wes.army.mil/library/publications/cetn/.

Kraus, N. C., Mark, D. J., and Sarruff, S. (2000). "DMS: Diagnostic Modeling System, Report 1: Reduction of sediment shoaling by relocation of the Gulf Intracoastal Waterway, Matagorda Bay, Texas," ERDC/CHL TR-00-19, U.S. Army Engineer Research and Development Center, Vicksburg, MS.

Ozsoy, E. E., and Ünlüata, Ü.,U. (1982). "Ebb-tidal flow characteristics near inlets,” Estuarine, Coastal and Shelf Science 14, 251-263.

Pope, J. (1997). "Where and why inlet channels shoal: a conceptual geomorphic framework," Coastal Engineering Technical Note CETN-IV-12, U.S. Army Engineer Research and Development Center, Vicksburg, MS, http://chl.wes.army.mil/library/publications/cetn/.

Pratt, T. C., and Cook, D. S. (2000). "Hydraulic Processes Analysis System (HyPAS)," ERDC/CHL CETN-IV-23, U.S. Army Engineer Research and Development Center, Vicksburg, MS, http://chl.wes.army.mil/library/publications/cetn/.

Rosati, J. D., and Kraus, N. C. (1999). "Shoal-reduction strategies for entrance channels," Coastal Engineering Technical Note CETN IV-22, U.S. Army Engineer Research and Development Center, Vicksburg, MS, http://chl.wes.army.mil/library/publications/cetn/. 
ERDC/CHL CETN-IV-28

September 2000

Van Rijn, L. C. (1984). "Sediment Transport, Part I: Bed Load Transport," Journal of Hydraulic Engineering, 110(10). 